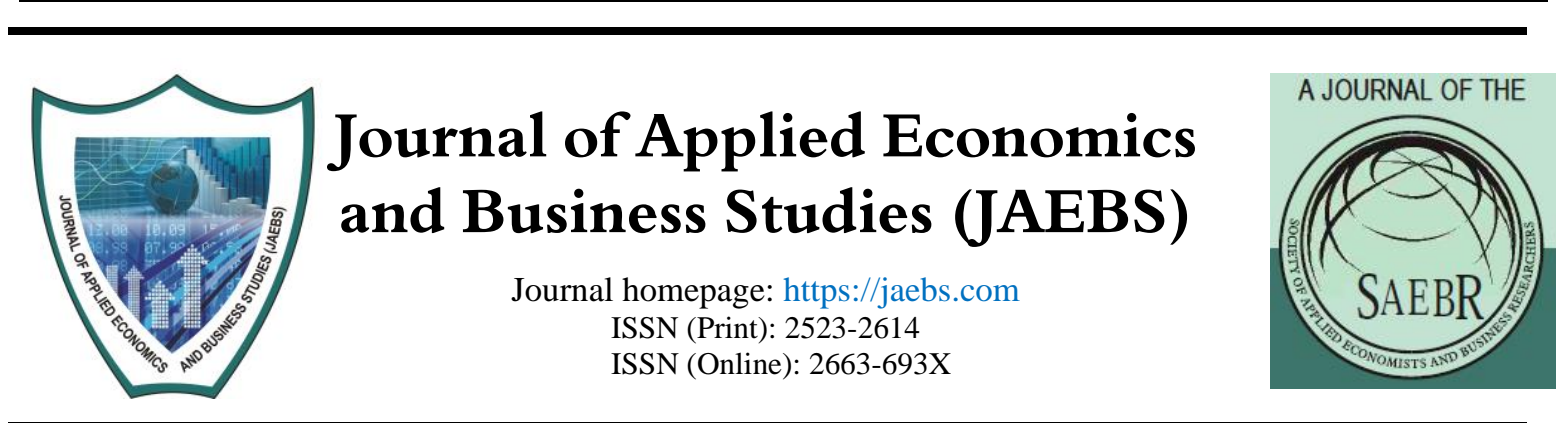

\title{
Impact of corporate social responsibility guidelines 2013 on the extent of the corporate social responsibility activities and disclosures in Pakistan
}

Maqsood Hayat ${ }^{1 *}$, Shehzad Khan ${ }^{2}$

${ }^{1} \mathrm{PhD}$ Scholar, Yunnan University of Finance and Economics, Kunming, China

${ }^{2}$ Assistant Professor, Institute of Business Studies and Leadership, Abdul Wali Khan University Mardan.

\begin{abstract}
The main objective of this study was to examine the impact of CSR guidelines 2013 on the level of corporate social responsibilities (CSR) activities and their disclosure in Pakistan. This study analyzed the voluntary disclosure guidelines impact on various stakeholders of the top companies of the year listed in Pakistan's stock exchange for the five years (2011-2015). It is found that the introduction of these guidelines 2013 had a positive impact on the overall level of corporate social responsibilities disclosures (CSRD). It was also observed that the overall trends in the level of CSRD increased gradually within the sample period. There need to be continuous a requirement through regulations and local pressures on the firms for engaging in ethical business practices and to disclose that information to government organizations and general public. Corporations can gain both economically and ethically when they take CSR as marketing and public relation opportunity. Finally, corporations can give itself edge by distinguishing its operations from others and therefore gain competitive advantage.
\end{abstract}

Keywords CSR, CSR

Guidelines, CSR Disclosure JEL Classification M14, M10, M19

Copyright $\odot 2018$ SAEBR - All rights reserved

\section{Introduction}

Corporate social responsibility (CSR) has always been in practice in various forms. However, the modern structure of CSR originated in the early decades of the 20th century. Thereafter, it got extensive attention in corporate practices and academic research. International bodies have been striving hard to unify the reporting format for all the businesses across the globe. Misani (2010) examined whether firms adopt convergence or divergence in practicing the CSR and argued that firms are expected to incorporate CSR in their business model due to pressures from various stakeholders such as its customers,

\footnotetext{
*Corresponding author: drhayat2019@gmail.com
} 
governments and non-governmental organizations. Firms in developing countries and emerging economies are also forced to follow similar guidelines with respect to CSR as their counterparts in developed countries due to globalization and free trade agreements. Socially and environmentally sensitive stakeholders expect more from business communities to be both socially and environmentally responsible besides merely profitable. Corporate social responsibility disclosure (CSRD) is getting mandatory in many countries, and thus corporations implement CSR activities which ultimately increase the corporate value of the firms in the context of local priorities of the society (Manchiraju \& Rajgopal, 2015). Corporate social responsibility is an amalgam of various activities such as wellbeing of the general public, environmental and biodiversity sustainability, and improvement in the wellbeing of both the owners and other stockholders. Therefore, CSR focuses on allowing the firms to operate in such a way to not only generate profit for the owners but to also promote overall prosperity. Corporate social responsibility enforces the corporation to behave morally inside the organization premises and act like a good citizen outside the organization boundary.

Large multinationals such as McDonald and Marks \& Spencer have adopted comprehensive CSR framework that takes into account the economic, social, environmental and other benefits both for the business and stockholders. Enterprises vary in terms of the scale of the adoption of the CSR as some only adopts a limited set of activities compared to others which adopt a comprehensive one. Most of the enterprises disclose their CSR reports via different channels to target a wide cluster of stakeholders. Information in the disclosure reports with respect to CSR activities determine the characteristics and nature of the organizations. Corporations are pressurized by stakeholders to be responsible and accountable not only for their economic liability but also for social and environmental accountability. The benefits range of CSR are widespread which may include transparency in hiring, proper training, healthy and secure working environment for employees. Similarly, the consumer related activities such as provision of safe and reliable products, disclosing the details about the product ingredients and manufacturing process. Therefore, it is crucial for enterprises to streamline their corporate strategy and specify the corporate activities that are sensitive towards the local norms, social values, religious beliefs, and organizational strength \& features. Corporate benefits achieved through adopting CSR activities have already been examined by numerous authors in their research studies (e.g. Kurucz et al, 2008; Mullerat, 2010; Perry and Towers, 2013; Porter and Kramer, 2006).

Corporate social responsibility is voluntarily in some parts of the world while legally required and enforced in other parts of the world. However, corporate social responsibility and corporate accountability need to be differentiated to avoid unnecessary demands from stakeholders and let the organizations to operate within their jurisdictions (Cash, 2012). The main drivers behind the CSR activities are not only external forces in the shape of 62 
governmental regulations and stakeholder's activism but also corporate self-regulation. Other forces that pressurize the corporations stem from society, non-profitable organizations, media, religious leaders, suppliers, buyers and employees. Campbell (2007) observed that corporations are more inclined to behave in a socially responsible way when their activities are strictly observed by many stakeholders. The issue of CSR in Pakistan was first time highlighted when the use of child labour and sweatshops were found by the international humanitarian organization in local sports and carpet industries of Pakistan. This leads to the multilateral consortium called the "Pakistan Compliance Initiative" in 2003 to monitor the business activities and eliminate the unethical and illegal use of workforce in Pakistan. The initiative to implement CSR activities in corporate operations was taken first time by a general order from the Security Exchange Commission of Pakistan (SECP) in 2009. Unfortunately, due to the unavailability of specific reporting CSR format, the corporations took it as a tool of public relation and corporate promotion. In true sense, there are only a few laws and regulations regarding CSR in Pakistan, issued by SECP and State Bank of Pakistan (SBP). Apart from these orders and guidelines, there are other laws provided under the constitution of Pakistan which have some relevancy to CSR regulations. Few of them are corporate laws, environmental laws; labour laws and consumer protection laws. The CSR voluntary guidelines 2013 were issued from SECP, with the basic purpose to streamline the corporate activities and measure the corporate efficiency regarding all stakeholders. Therefore, enterprises operating in Pakistan and especially that are listed in any stock exchange of Pakistan should seriously consider the importance of these guidelines to avoid any discrepancy for violation of the rules and regulations of the country. The major objectives of this study is to examine the effectiveness of the voluntary CSR guidelines 2013 and its impact on the level of CSRD practiced by the firms listed in the Pakistan stock exchange. This study is an attempt to examine the pre and post effect of the various dimensions of the local CSR guidelines.

\section{Literature review}

Clark (1939) was the pioneer of the modern CSR which was then refined by Bowen (1953). Although the initial empirical research was done in 1976 by Bowman and Haier (1976), however, this idea was revitalized by Carroll (1991) by introducing four dynamics of CSR in hierarchal order such as economic, legal, ethical, philanthropic which is called the CSR pyramid. Later on, Elkington (1997) introduced the concept of the triple bottom line (TBL) approach by integrating three dynamics of CSR outputs also called the 3Ps model. Developing countries due to lack of awareness and expertise in the field of CSR and unwillingness of corporations to collaborate with the local community do not follow specific CSR guidelines (Jamali and Miurshak, 2007). These corporations are adopting CSR activities in their corporate strategies due to stakeholder's activism. These CSR activities 
are not helpful if not communicated to stakeholders properly. Therefore, the corporation should have a strict observation and enough knowledge to classify their stakeholders needs and to prioritize them to achieve corporate benefits. To reap the maximum benefits from the CSR investment, the corporations should have a proper strategy to implement CSR in business operations. Most of the corporations are unwilling to disclose every aspect of their corporate activities to a wide range of stakeholders in a more transparent way. Rawlins (2008) observed that corporate transparency is different than just disclosing information to the public. Full and neutral information disclosure can lead to corporate credibility and gain the public confidence.

Martinson (1996) reported that the basic meaning of transparency is to truthfully communicate the reality of a particular subject-incident-event to the stakeholders. Corporations need to release most information related to their stakeholders. Many organizations work in close collaboration with corporate community and stakeholders to formulate a reporting format which is acceptable for all type of corporations and in line with stakeholders' demands. Cavanagh (2004) reported that United Nations Declaration of Human Rights (1948) and the International labour Organization's Tripartite Declaration (1977) are important for the CSR activities too. In addition, other reporting formats such as Socially Responsible Investing groups, Dow Jones Sustainability Index, Global 100, United Nations Global Compact, The Global Reporting Initiatives, Kinder Lindenberg and Domini are not only useful for investors but also for other stakeholders. Sometimes it is difficult for small businesses in developing countries to understand the strict CSR criteria, which ultimately discourage the domestic firms to incorporate and report such a complicated guideline in their business activities (Perera, 2008). Therefore, it is crucial to develop a universal legal agenda for all corporations to design a specific CSR format, which is acceptable enterprises globally. Other scholars are in the view that CSR expectations vary from culture to culture due to their formal and informal regulations, i.e. societal, economic and political circumstances (Carroll, 2004; Cummings \& Guthrie, 2007; Matten \& Moon, 2008). Local governments in developing countries are taking initiatives to introduce the guidelines with a view to encourage businesses to focus more on social and environmental development (Campbell, 2007).

Several studies have been conducted on the importance of CSR across the globe, especially in the developed countries mainly in the US and Europe. Many researchers (Clarkson, 1995; Samiee \& Athanassiou, 1998) stated that there is a need for universal guidelines for CSR. Wood (2010) criticized that most of research relating to CSR is undertaken in developed countries. Jamali and Miurshak (2007) reported that due to lack of awareness, corporations in developing countries generally do not practice CSR. Therefore, it is important to study the CSR in the developing countries context as well. 
Pakistan is faced with many social, economic, political and environmental issues. Like other developing countries, Pakistan lacks resources to fulfil the basic needs of the general public and to build infrastructure. Few studies have been conducted on CSR in Pakistan due to political uncertainty, widespread corruption, immoral corporate culture, human rights abuse, unemployment, and environmental problems (Jhatial et al, 2014). The widespread differences in norms and values are also the biggest hurdles in formulating the CSR strategy in Pakistan. Most of the time, enterprises are reluctant to resolve the local issues because of complexity and sensitivity. Naeem \& Welford (2009) investigated that the CSR dimensions in Pakistan are not aligned with the standards of the global compact principles (GCP). In Pakistan, the concept of CSR has been promulgated by multinational corporations (MNCs) like Nestle and Unilever. Similarly, local enterprises like various banks provide assistance in grooming talent, and other donations in health and education sectors. Lund-Thomsen \& Nadvi (2010) studied the impact of international and domestic regulations in the leather industry of Pakistan, while Hussain-Khaliq (2004) investigated the sports industry of Pakistan and explored the exploitation of the child labour in the football industry. There is also a growing awareness of the importance of environmental safety and protection in Pakistan.

Many organizations run campaigns regarding the environment and health every year. Some advocacy associations such as the National Forum of Environment and Health (NFEH) presents annual excellence awards for the best performance in environment, health, education, and socio-economic development. Pasha and Liesivuori (2003) found that most of the company workforce are uneducated and not trained in occupational health and safety (OHS) procedures. Similarly, Jeswani et al (2008) reported that $75 \%$ of the Pakistani enterprises face many hurdles to adopt and implement CSR in their corporate strategies. These hurdles are lack of awareness, insufficient financial resources, the absence of regulatory framework and policies, unavailability of technology and shortage of expertise to deal with complex environmental issues.

It is clear from the above discussion that all the CSR guidelines have a wide scope and cover almost all the CSR theories. These guidelines relate to shareholders' theory as profit on investment and firm value is addressed. Similarly, the CSR guidelines are in conformity with the stakeholder's theory, Carroll CSR pyramid, and legitimacy theory too.

\section{Research methods}

CSR related data were collected from the annual reports published by the "Top 25 companies of the year" for five years (2011-2015). Individual list was prepared for all enterprises and only those enterprises were selected which had corporate websites and published annual reports for the sample period. A total sample of 51 companies were selected for this study. 
Different techniques have been used to measure the CSR. Some of the previous studies used corporate internal information for measuring the CSR level such as annual reports and social and sustainability reports (Hart and Ahuja, 1996; Muoghalu et al, 1990). These indicators were compared with the international standardized reporting agencies format such as KLD, GRI, ILO, ISO and looked for availability or unavailability of various measures therein. This study calculates the level of CSRD by measuring the economic, philanthropic, legal, ethical, investor, employee, customer, community, health, education, sports, environment and government CSR indicators with the help of content analysis (CA hereinafter). CA was used by a number of researchers in their social and environmental reporting for classifying the social reporting dimensions of disclosing corporations (e.g. Adams et al, 1995; Adams and Harte, 1999; Milne and Adler, 1999; Beck et al, 2010). Berelson (1952) describes that CA is the research method for the objective, systematic and quantitative description of the manifest content of the communications. This CA concept has been further defined by Guthrie et al (2004) as a technique for gathering data contained in the annual reports and it involves codifying qualitative and quantitative information into pre-defined categories in order to derive patterns in the presentation and reporting of information. Every document was scanned manually line by line and word by word to assure the authenticity and quality of the desired extracted data. The text was scanned against the predefined parameters and was codified with " 1 " per sentence, as one sentence is equalized to "1". This type of technique was also adopted by other researchers (e.g., Eng and Mak, 2003; Haniffa and Cooke, 2002).

Descriptive statistics are used to define, summarize and measure the elementary structures of the collected data and sample in the research study. Paired sample t-test, also known as the dependent sample t-test, is used to examine the differences in mean values of the two sets. Paired sample t-test is conducted in a context of the unequal variance in both samples. In this way, the pre and post effect of the CSR guidelines 2013 was examined in a given sample of the study to certify the projected proposition, with an assumption to be rejected or accepted.

\section{Results and discussion}

The statistical summary of various stakeholders and the layers of CSR's pyramid is presented in table 1. Investor is the first group of internal stakeholders, which has an average value of 11.93 with a stand deviation of 17.67. The employees have mean value 30.89 . Further, the customer, community, and environmental disclosure have the average values of $11.79,10.17,21.85$ respectively. The average values of the economic layer, philanthropic layer, legal layer, and ethical layer were 69.92, 38.71, 64.23, and 7.94 respectively. The results show in the table 1 that the economic aspect of the pyramid was the most important of the CSR activities. The firms got to be profitable before it can look for other CSR 
activities. Further, working under the legal framework was also found to be very important activity of the CSR.

Table 1: Descriptive statistics of the relevant CSR categories

\begin{tabular}{|l|c|c|c|c|c|}
\hline & Mean & Median & Std. Dev & Min & Max \\
\hline CSR & 180.81 & 135.90 & 155.82 & 0.00 & 869.00 \\
\hline Investor & 16.65 & 11.93 & 17.67 & 0.00 & 91.75 \\
\hline Employee & 30.89 & 21.21 & 31.52 & 0.00 & 185.20 \\
\hline Customer & 23.68 & 11.79 & 28.55 & 0.00 & 139.50 \\
\hline Community & 20.20 & 10.17 & 33.66 & 0.00 & 280.00 \\
\hline Environment & 21.85 & 9.33 & 37.36 & 0.00 & 240.50 \\
\hline Economic & 69.92 & 53.66 & 54.36 & 0.00 & 256.19 \\
\hline Philanthropic & 38.71 & 20.46 & 47.66 & 0.00 & 312.00 \\
\hline Legal & 64.23 & 40.34 & 73.22 & 0.00 & 436.81 \\
\hline Ethical & 7.94 & 5.50 & 8.25 & 0.00 & 36.50 \\
\hline
\end{tabular}

Figure 1 show CSR disclosures for the given period of the study (2011-2015). These dimensions have been divided into 13 different categories to calculate the level of CSRD of the top 25 companies operating in Pakistan. It is indicated that the total 13 dimensions were measured in 100 percent terms. The workforce disclosure $(16.37 \%)$ seemed to the most important one followed by financial disclosure $(16.37 \%)$, product disclosure $(13.10 \%)$, environment $(12.09 \%)$, community $(11.17 \%)$, investors $(9.21 \%)$, ethics $(4.39 \%)$, compliance $(4.22 \%)$, education/Art $(4.19 \%)$, health $(2.88 \%)$, donation $(2.51 \%)$, government $(2.13 \%)$ and sports $(0.66 \%)$.

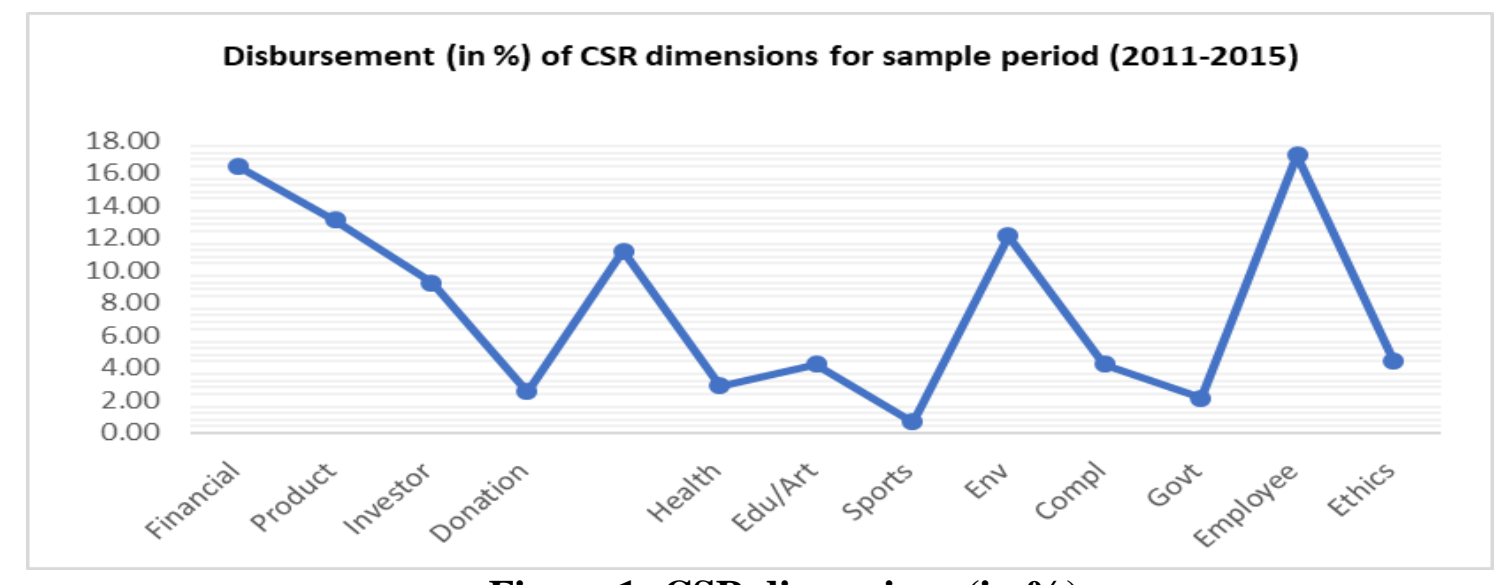

Figure 1: CSR dimensions (in \%)

Figure 2 indicates the year-wise total CSRD related to different stakeholders (i.e. investors, employees, customers, community and environment) and pyramid's layers (i.e. economic, philanthropic, legal and ethical). It shows an increasing trend over time. 


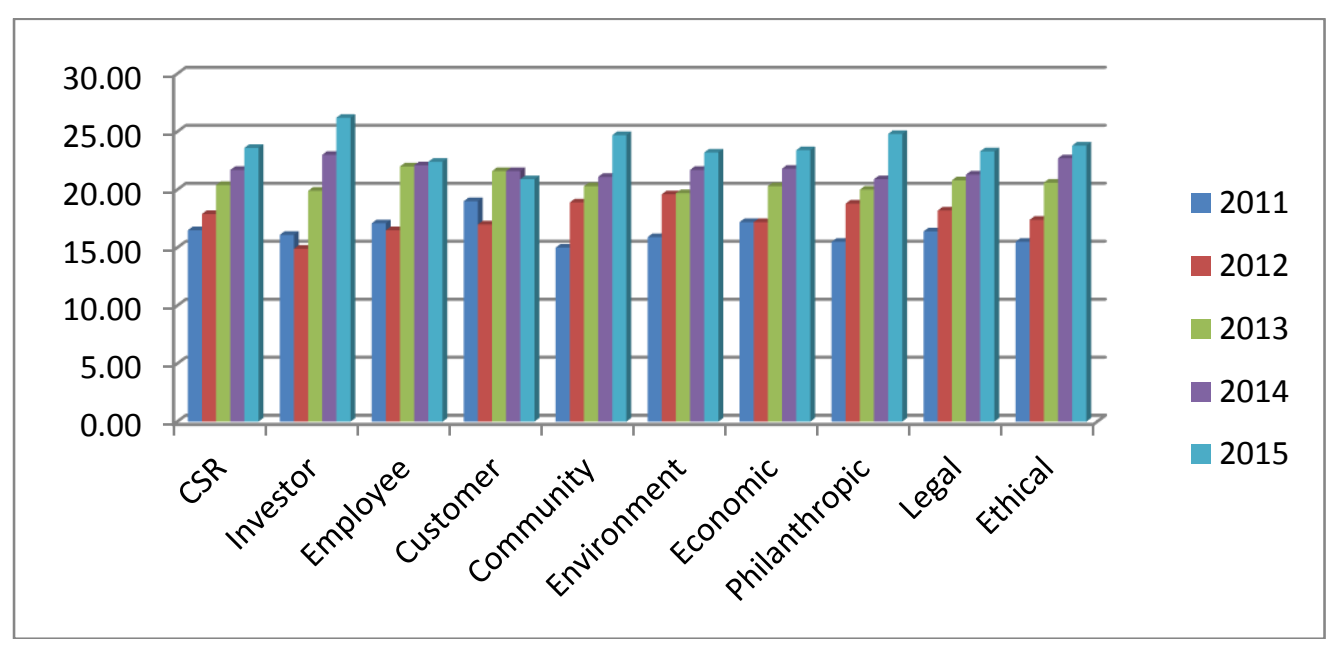

Figure 2: Proportionate (in \%) of CSRD indicators (Year-wise)

Figure 3 shows the year wise fluctuation in the level of total CSRD related to different stakeholders (i.e. investors, employees, customers, community and environment) and pyramid's layers (i.e. economic, philanthropic, legal and ethical).

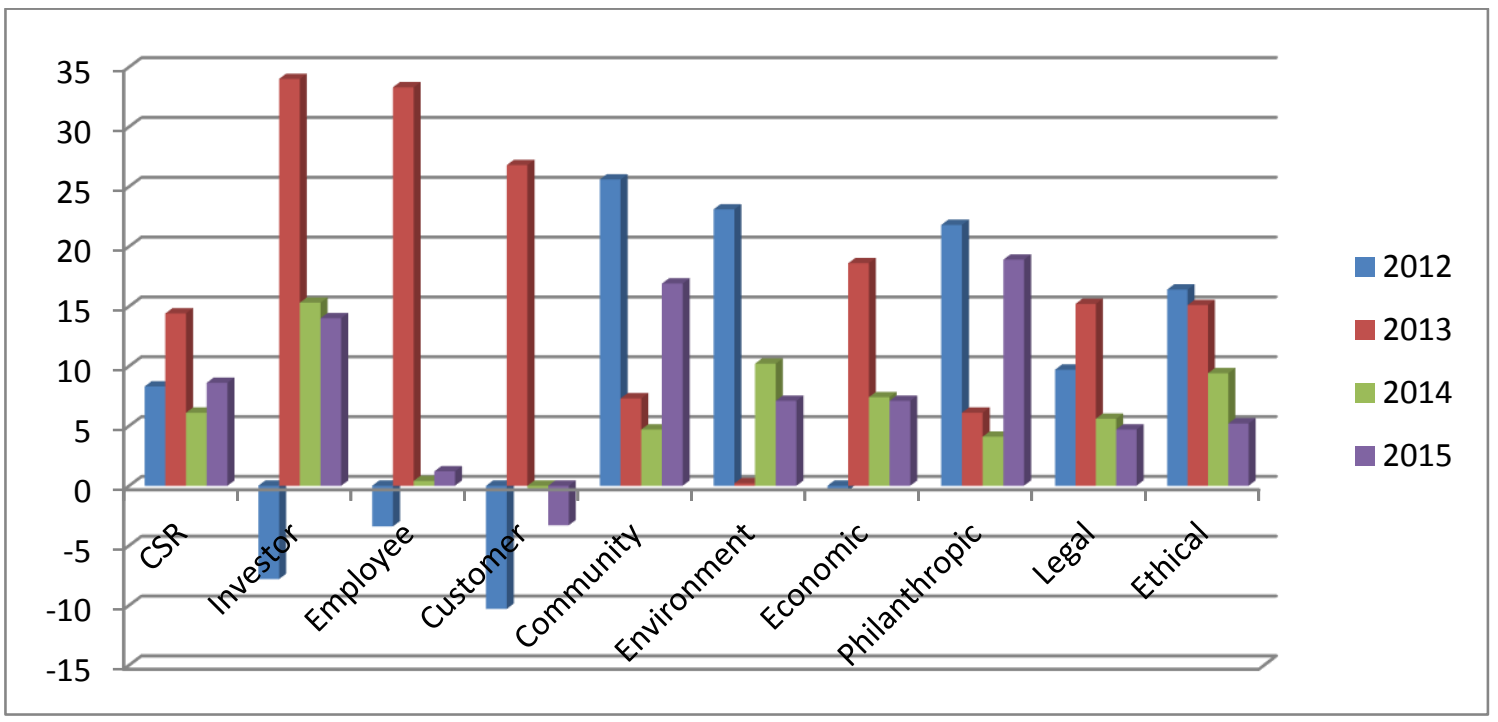

Figure 3: Yearly changes in CSRD indicators

Figure 4 and table 2 show the effect of voluntary CSR guidelines 2013 on the level of CSRD. Both the pre and post CSR guidelines are compared, and the change is calculated. 
Table 2: Impact of "voluntarily CSR guidelines 2013" (Pre-2013 V/S Post-2013)

\begin{tabular}{|l|ccc|}
\hline & Pre-13 & Post-13 & Change \\
\hline Total CSR & 34.3 & 45.2 & 31.7 \\
Financial & 35.0 & 45.4 & 29.7 \\
Customer & 36.0 & 42.4 & 17.8 \\
Investor & 31.0 & 49.1 & 58.6 \\
Donation & 28.8 & 50.5 & 75.2 \\
Community & 33.9 & 45.8 & 35.3 \\
Health & 39.1 & 42.0 & 7.4 \\
Education/Art & 36.4 & 43.3 & 19.0 \\
Sports & 30.9 & 53.4 & 72.8 \\
Environment & 35.5 & 44.8 & 26.2 \\
Compliance & 35.0 & 46.0 & 31.3 \\
Govt & 33.7 & 46.0 & 36.5 \\
Employee & 33.6 & 44.4 & 32.3 \\
Ethics & 33.3 & 46.2 & 38.9 \\
\hline
\end{tabular}

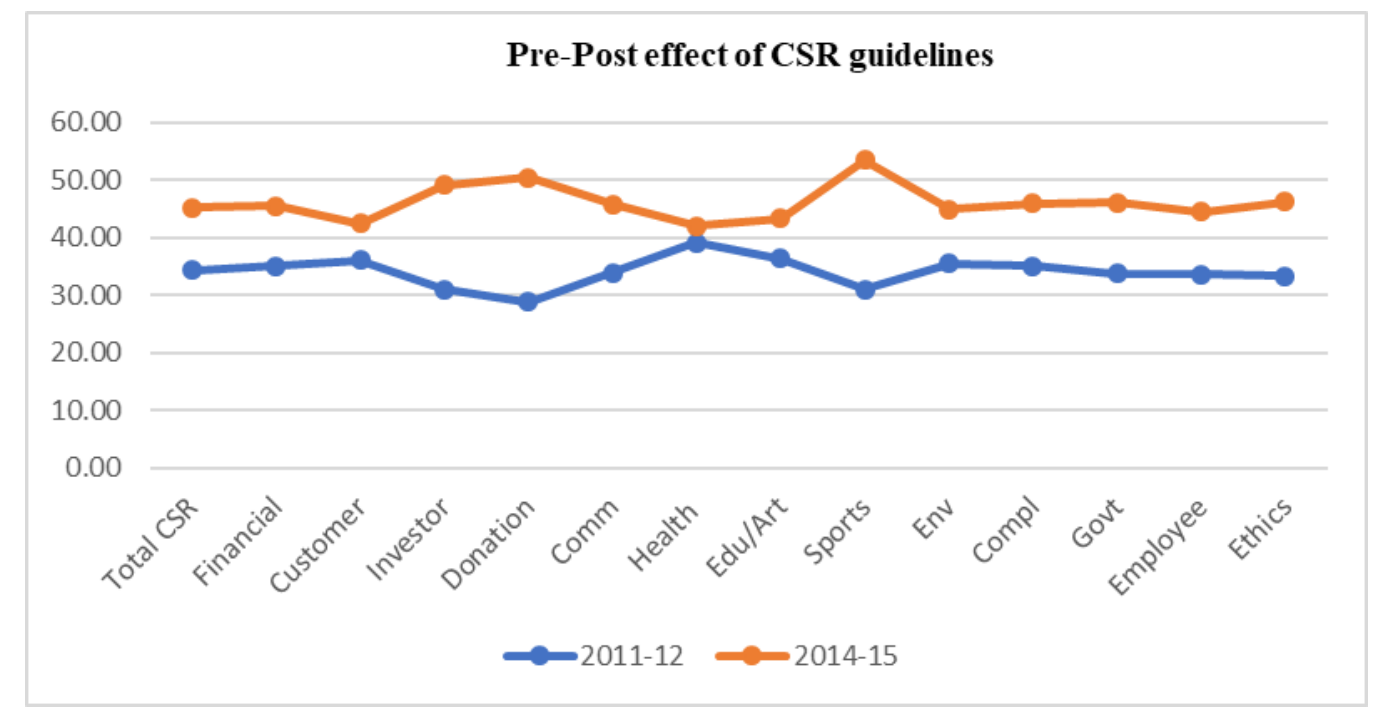

Figure 4: Impact of "Voluntarily CSR guidelines 2013" (Pre-2013 V/S Post-2013)

Results above shows the pre and post CSR 2013 guidelines changes in absolute terms. Following in table 3, we present the comparison of the CSR results statistically using the pair t-test. The mean values for all CSR categories indicate progressively increasing trend after the implementation of CSR guidelines in 2013. The mean value for the total CSRD increased to 204.42 post 2013 from the pre 2013 of 155.25, and this difference is also statistically significant at 1 per cent level. The observed increase in the level of CSRD over the sample period (2011-2015) can be linked with the stakeholder and institutional theories. Gao et al (2005) conducted a study in Hong Kong and examined that the level of CSRD increasing between 1993 and 1997. Similarly, Mahadeo et al (2011) recognized the 
increasing trends of the CSRD over a period of four years (2004-2007) in Mauritius. Haniffa and Cooke (2005) conducted a study in Malaysia and examined that the level of CSRD increased in the sample period (1996-2002). In another study in the context of Malaysia, Esa and Ghazali (2012) investigated that the degree of the CSRD increased between 2005 and 2007 in the annual reports of government-linked corporations. Haji (2013) also confirmed the increased level of CSRD in Malaysian context in the annual reports of Malaysian listed firms from 2006 to 2009. The same results were also observed by Ratanajongkol et al (2006) in the context of Thailand. Similarly, the mean values for the entire stakeholder group increased after the announcement of the CSR guidelines in 2013. The investor related disclosure also increased to mean value of 20.44 in post 2013 compared to 12.89 in pre-2013 period. Employee-related disclosure, and the customer and community related CSRD were higher in the post-2013 era compared to that of the pre-2013 and also this difference were significant at 5 per cent level. Environment-related CSRD is the last indicator of the stakeholder group which was higher in post 2013 era however this difference has not been statistically significant. Regarding Carroll's pyramid, the t-test reveals that all the four layers are statistically significant. The mean values in pre-2013 for economic, philanthropic, legal and ethical layers are 60.11, 33.26, 55.27 and 6.60, which increased gradually to $79.11,44.15,71.99$ and 9.17 in post-2013 respectively.

Table 3: Pre-post effect of CSR guidelines 2013

\begin{tabular}{|c|c|c|c|c|c|c|}
\hline Dimension & Pre/Post & Mean & Observations & d.f & t-Stat & P-value \\
\hline \multirow{2}{*}{ CSR } & Pre-2013 & 155.25 & 96 & 95 & -4.29 & $* * *$ \\
\hline & Post-2013 & 204.42 & 96 & & & \\
\hline \multirow{2}{*}{ Investor } & Pre-2013 & 12.89 & 96 & 95 & -4.18 & $* * *$ \\
\hline & Post-2013 & 20.44 & 96 & & & \\
\hline \multirow{2}{*}{ Employee } & Pre-2013 & 25.94 & 96 & 95 & -3.47 & $* * *$ \\
\hline & Post-2013 & 34.31 & 96 & & & \\
\hline \multirow{2}{*}{ Customer } & Pre-2013 & 21.32 & 96 & 95 & -2.22 & $* *$ \\
\hline & Post-2013 & 25.09 & 96 & & & \\
\hline \multirow{2}{*}{ Community } & Pre-2013 & 17.1 & 96 & 95 & -2.31 & $* *$ \\
\hline & Post-2013 & 23.18 & 96 & & & \\
\hline \multirow{2}{*}{ Environment } & Pre-2013 & 19.41 & 96 & 95 & -1.72 & \\
\hline & Post-2013 & 24.49 & 96 & & & \\
\hline \multirow{2}{*}{ Economic } & Pre-2013 & 60.11 & 96 & 95 & -4.91 & $* * *$ \\
\hline & Post-2013 & 79.11 & 96 & & & \\
\hline \multirow{2}{*}{ Philanthropic } & Pre-2013 & 33.26 & 96 & 95 & -2.75 & $* * *$ \\
\hline & Post-2013 & 44.15 & 96 & & & \\
\hline \multirow{2}{*}{ Legal } & Pre-2013 & 55.27 & 96 & 95 & -2.98 & $* * *$ \\
\hline & Post-2013 & 71.99 & 96 & & & \\
\hline \multirow{2}{*}{ Ethical } & Pre-2013 & 6.6 & 96 & 95 & -4.41 & $* * *$ \\
\hline & Post-2013 & 9.17 & 96 & & & \\
\hline
\end{tabular}

$* * *, * *$ and $*$ indicates significant level at $1 \%, 5 \%$ and $10 \%$ respectively 


\section{Conclusion}

The main objective of this study was to investigate the impact of the voluntarily CSR guidelines 2013 on the corporate social responsibility disclosures (CSRD). Corporate social responsibility (CSR) related data were collected from the annual reports published by the "Top 25 companies of the year" for five years (2011-2015). Individual list was prepared for all enterprises and only those enterprises were selected which had corporate websites and published annual reports for the sample period. A total sample of 51 companies were selected for this study. Comparison of the CSRD was done both in absolute terms and statistically through using the comparison of the means tests. The total level of CSRD increased over the period of time in all five years, with an increase of $43 \%$ from the year of inception (2011). The results of the study also suggest that the level of overall CSRD increased with the introduction of the "CSR guidelines 2013". Similarly, the CSRD related to community, environment, economic, philanthropic, legal and ethical indicators increased in all five years too. This can be attributed to the gradual increase in the awareness of the stakeholders and their sensitivity towards ethical business and the importance of reporting CSR activities to avoid any discrepancy for violation of the rules and regulations in the country. Similarly, the impact was also tested for various groups of stakeholders and layers of CSR's pyramid. It was found that the level of CSRD for all indicators was recorded positive and statistically significant in the post-2013 era except the environmental dimension. There need to be continuous a requirement through regulations and local pressures on the firms for engaging in ethical business practices and to disclose that information to government organizations and general public. Corporations can take CSR as marketing and public relation opportunity. Therefore, the corporations need to formulate, strategize and implement these guidelines in corporate operation to achieve a distinguished position among the competitors, even if it is not obligatory by the government. The government should encourage the corporations to report beyond the boundary of the obligatory limits to satisfy the demands of the overall stakeholder, especially the active stakeholder groups.

\section{References}

Adams, C. A., Hill, W. Y., \& Roberts, C. B. (1995). Environmental, employee and ethical reporting in Europe. London: Certified Accountants Educational Trust.

Adams, C., \& Harte, G. (1999). Towards corporate accountability for equal opportunities performance. ACCA occasional research paper no. 26. London: ACCA.

Beck, A. C., Campbell, D., \& Shrives, P. J. (2010). Content analysis in environmental reporting research: Enrichment and rehearsal of the method in a British-German context. The British Accounting Review, 42(3), 207-222.

Berelson, B. (1952). Content analysis in communication research.

Bowen, H.R. Social responsibilities of businessmen (1953). New York: Harper \& Brothers. 
Bowman, E. H., \& Haire, M. (1976). Social impact disclosure and corporate annual reports. Accounting, Organizations and Society, 1(1), 11-21.

Campbell, J. L. (2007). Why would corporations behave in socially responsible ways? An institutional theory of corporate social responsibility. Academy of management Review, 32(3), 946-967.

Carroll, A. B. (1991). The pyramid of corporate social responsibility: Toward the moral management of organizational stakeholders. Business horizons, 34(4), 39-48.

Carroll, A. B. (2004). Managing ethically with global stakeholders: A present and future challenge. Academy of Management Perspectives, 18(2), 114-120.

Cash, A. C. (2012). Corporate social responsibility and petroleum development in subSaharan Africa: The case of Chad. Resources Policy, 37(2), 144-151.

Cavanagh, G. F. (2004). Global business ethics: Regulation, code, or self-restraint. Business Ethics Quarterly, 14(4), 625-642.

Chalmers, K., \& Godfrey, J. M. (2004). Reputation costs: the impetus for voluntary derivative financial instrument reporting. Accounting, Organizations and Society, 29(2), 95-125.

Clark, J.M. Social control of business (1939). 2nd ed. New York: McGraw Hill.

Clarkson, M. E. (1995). A stakeholder framework for analyzing and evaluating corporate social performance. Academy of management review, 20(1), 92-117.

Cummings, L. S., \& Guthrie, J. (2007). Managerial attitudes toward stakeholder salience within selected western Pacific-Rim economies. Journal of Asia-Pacific Business, $8(1), 7-29$.

Elkington, J. (1997). Partnerships from cannibals with forks: The triple bottom line of 21stcentury business. Environmental quality management, 8(1), 37-51.

Eng, L. L., \& Mak, Y. T. (2003). Corporate governance and voluntary disclosure. Journal of accounting and public policy, 22(4), 325-345.

Esa, E., \& Anum Mohd Ghazali, N. (2012). Corporate social responsibility and corporate governance in Malaysian government-linked companies. Corporate Governance: The international journal of business in society, 12(3), 292-305.

Gao, S. S., Heravi, S., \& Xiao, J. Z. (2005, June). Determinants of corporate social and environmental reporting in Hong Kong: a research note. In Accounting Forum (Vol. 29, No. 2, pp. 233-242). Taylor \& Francis.

Guthrie, J., Petty, R., Yongvanich, K., \& Ricceri, F. (2004). Using content analysis as a research method to inquire into intellectual capital reporting. Journal of intellectual capital, 5(2), 282-293.

Ahmed Haji, A. (2013). Corporate social responsibility disclosures over time: evidence from Malaysia. Managerial auditing journal, 28(7), 647-676.

Haniffa, R. M., \& Cooke, T. E. (2005). The impact of culture and governance on corporate social reporting. Journal of accounting and public policy, 24(5), 391-430.

Haniffa, R. M., \& Cooke, T. E. (2002). Culture, corporate governance and disclosure in Malaysian corporations. Abacus, 38(3), 317-349. 
Hart, S. L., \& Ahuja, G. (1996). Does it pay to be green? An empirical examination of the relationship between emission reduction and firm performance. Business strategy and the Environment, 5(1), 30-37.

Hussain-Khaliq, S. (2004). Eliminating child labour from the Sialkot soccer ball industry: Two industry-led approaches. Journal of Corporate Citizenship, (13), 101-107.

Jamali, D., \& Mirshak, R. (2007). Corporate social responsibility (CSR): Theory and practice in a developing country context. Journal of business ethics, 72(3), 243-262.

Jeswani, H. K., Wehrmeyer, W., \& Mulugetta, Y. (2008). How warm is the corporate response to climate change? Evidence from Pakistan and the UK. Business Strategy and the Environment, 17(1), 46-60.

Jhatial, A. A., Cornelius, N., \& Wallace, J. (2014). Rhetorics and realities of management practices in Pakistan: Colonial, post-colonial and post-9/11 influences. Business History, 56(3), 456-484. 456-484.

Kinderman, D. (2009). The political economy of corporate responsibility across Europe and beyond: 1977-2007. Department of Political Science Ithaca, NY, Cornell University.

Kolk, A., \& Perego, P. (2010). Determinants of the adoption of sustainability assurance statements: An international investigation. Business strategy and the environment, 19(3), 182-198.

Lund-Thomsen, P., \& Nadvi, K. (2010). Global value chains, local collective action and corporate social responsibility: a review of empirical evidence. Business Strategy and the Environment, 19(1), 1-13.

Mahadeo, J. D., Oogarah-Hanuman, V., \& Soobaroyen, T. (2011). A longitudinal study of corporate social disclosures in a developing economy. Journal of Business Ethics, 104(4), 545-558.

Manchiraju, H., \& Rajgopal, S. (2015). Does corporate social responsibility (CSR) create shareholder value? Exogenous shock-based evidence from the Indian Companies Act 2013.

Matten, D., \& Moon, J. (2008). "Implicit" and "explicit" CSR: A conceptual framework for a comparative understanding of corporate social responsibility. Academy of management Review, 33(2), 404-424.

Milne, M. J., \& Adler, R. W. (1999). Exploring the reliability of social and environmental disclosures content analysis. Accounting, Auditing \& Accountability Journal, 12(2), 237-256.

Misani, N. (2010). The convergence of corporate social responsibility practices. Management Research Review, 33(7), 734-748.

Mullerat, R. (2010). International corporate social responsibility: the role of corporations in the economic order of the 21st century. Kluwer Law International BV.

Muoghalu, M. I., \& Robison, H. D. (1990). Hazardous Waste Lawsuits, Stockholder Returns, and Deterrence. Southern Economic Journal, 57(2).

Naeem, M. A., \& Welford, R. (2009). A comparative study of corporate social responsibility in Bangladesh and Pakistan. Corporate Social Responsibility and Environmental Management, 16(2), 108-122. 
Pasha, T. S., \& Liesivuori, J. (2003). Country profile on occupational safety and health in Pakistan (Report). International Labor Organization. Retrieved from http://www.ilo. org/safework/countries/asia/pakistan/WCMS_187800/lang-en/index.htm.

Perera, O. (2008). How material is ISO 26000 social responsibility to small and mediumsized enterprises? International Institute for Sustainable Development: Winnipeg, MB, Canada.

Perry, P., \& Towers, N. (2013). Conceptual framework development: CSR implementation in fashion supply chains. International Journal of Physical Distribution \& Logistics Management, 43(5/6), 478-501.

Kramer, M. P. Strategy and society: The link between competitive advantage and corporate social responsibility. Harvard Business Review.

Ratanajongkol, S., Davey, H., \& Low, M. (2006). Corporate social reporting in Thailand: The news is all good and increasing. Qualitative Research in Accounting \& Management, 3(1), 67-83.

Rawlins, B. (2008). Give the emperor a mirror: Toward developing a stakeholder measurement of organizational transparency. Journal of Public Relations Research, 21(1), 71-99.

Samiee, S., \& Athanassiou, N. (1998). International strategy research: cross-cultural methodology implications. Journal of Business Research, 43(2), 79-96.

Taylor, D., \& Darus, F. (2006). Mandatory disclosure's impact on voluntary disclosure of proprietary information: Evidence from introduction of financial instruments disclosure standard. In International Conference on Accounting and Finance in Transition (ICAFT), University of South Australia, (2006, 10-11 April).

Wood, D. J. (2010). Measuring corporate social performance: A review. International journal of management reviews, 12(1), 50-84. 